\title{
Induction of long-lived potential aestivation states in laboratory An. gambiae mosquitoes
}

\author{
Benjamin J. Krajacich ${ }^{*}$ (1), Margery Sullivan, Roy Faiman, Laura Veru, Leland Graber and Tovi Lehmann*
}

\begin{abstract}
Background: How anopheline mosquitoes persist through the long dry season in Africa remains a gap in our understanding of these malaria vectors. To span this period in locations such as the Sahelian zone of Mali, mosquitoes must either migrate to areas of permanent water, recolonize areas as they again become favorable, or survive in harsh conditions including high temperatures, low humidity, and an absence of surface water (required for breeding). Adult mosquitoes surviving through this season must dramatically extend their typical lifespan (averaging 2-3 weeks) to 7 months. Previous work has found evidence that the malaria mosquito An. coluzzii, survives over 200 days in the wild between rainy seasons in a presumed state of aestivation (hibernation), but this state has so far not been replicated in laboratory conditions. The inability to recapitulate aestivation in the lab hinders addressing key questions such as how this state is induced, how it affects malaria vector competence, and its impact on disease transmission.

Methods: In effort to induce aestivation, we held laboratory mosquitoes in climate-controlled incubators with a range of conditions that adjusted humidity $(40-85 \% \mathrm{RH})$, temperature $\left(18-27^{\circ} \mathrm{C}\right)$, and light conditions $(8-12 \mathrm{~h}$ of light) and evaluated their survivorship. These conditions were chosen to mimic the late rainy and dry seasons as well as relevant extremes these mosquitoes may experience during aestivation.

Results: We found that by priming mosquitoes in conditions simulating the late wet season in Mali, and maintaining mosquitoes in reduced light/temperature, mean mosquito survival increased from $18.34 \pm 0.65$ to $48.02 \pm 2.87$ days, median survival increased from $19(95 \% \mathrm{Cl} 17-21)$ to 50 days ( $95 \% \mathrm{Cl} 40-58)$, and the maximum longevity increased from 38 to 109 days $(P$-adj $<0.001$ ). While this increase falls short of the $200+$ day survival seen in field mosquitoes, this extension is substantially higher than previously found through environmental or dietary modulation and is hard to reconcile with states other than aestivation. This finding will provide a platform for future characterization of this state, and allow for comparison to field collected samples.
\end{abstract}

Keywords: Aestivation, Dry season, Anopheles, Malaria

*Correspondence: benjamin.krajacich@nih.gov; tlehmann@niaid.nih.gov Laboratory of Malaria and Vector Research, National Institute of Allergy and Infectious Diseases, National Institutes of Health, Rockville, MD 20852, USA

(C) The Author(s) 2020. This article is licensed under a Creative Commons Attribution 4.0 International License, which permits use, sharing, adaptation, distribution and reproduction in any medium or format, as long as you give appropriate credit to the original author(s) and the source, provide a link to the Creative Commons licence, and indicate if changes were made. The images or other third party material in this article are included in the article's Creative Commons licence, unless indicated otherwise in a credit line to the material. If material is not included in the article's Creative Commons licence and your intended use is not permitted by statutory regulation or exceeds the permitted use, you will need to obtain permission directly from the copyright holder. To view a copy of this licence, visit http://creativecommons.org/licenses/by/4.0/. The Creative Commons Public Domain Dedication waiver (http://creativecommons.org/publicdomain/zero/1.0/) applies to the data made available in this article, unless otherwise stated in a credit line to the data. 


\section{Background}

The goal to end the transmission of malaria causing Plasmodium spp. parasites has achieved significant gains since the recent peak of the early 2000s, though it appears progress may have slowed in sub-Saharan Africa in the last 2 years [1]. Currently, the majority of infected individuals $(>90 \%)$ are living in meso- or hypoendemic (defined as a Plasmodium falciparum parasitaemia rate in children aged 2-10 between 1-50\%) areas with seasonal transmission [2]. While Mali has a strong seasonal transmission cycle, with $\sim 7$ months of the year largely unconducive to mosquito presence, the rates of malaria have remained consistent [3], even with increasing intervention in the form of bednets [4], insecticide residual spraying [5], and other interventions. The reasons for this disease persistence are multifactored, but it is likely that the persistent nature of the vectors themselves play a role. Insecticide resistance has emerged broadly to all utilized insecticides [6], eradication of An. gambiae has only been possible in a few areas of the globe [7, 8], and the resilient seasonal return of malaria-causing vectors has been long known though with poorly understood mechanisms.

Evidence for long-lived aestivation, or dry-season diapause phenotypes have been described for over 100 years in Anopheles mosquitoes [9]. In Burkina Faso, collections of larvae and adult An. gambiae from the area around Bobo-Dioulasso showed the ability to live greater than 150 days when held in houses that were comparatively cooler, more humid, and less windy than the ambient air [10]. A similar finding was also reported with An. gambiae (likely contemporary An. arabiensis) from Sudan, where in the absence of suitable breeding habitat, mosquitoes were found resting in "dwelling huts in dark places between the thatched roofs and the median longitudinal beams" during the entirety of the 9 month dry season [11]. More contemporary work in Mali has highlighted the unique patterns in seasonal abundance of the three sibling species of the An. gambiae (s.l.) complex, with An. coluzzii mosquitoes showing presence throughout the arid 7 month dry season, An. gambiae (s.s.) being absent, and An. arabiensis showing an intermediate phenotype $[12,13]$. The An. coluzzii mosquitoes that do appear during the late dry season peak (a yearly, high density, 1-2-week event), host-seek normally, but exhibit reproductive depression compared with the wet season mosquitoes [14]. However, while this phenotype has been repeatedly described over the last century, the methodology to induce such a long-lived state with laboratory, colony mosquitoes has remained beyond reach.

Laboratory models of overwintering diapause have been reliably induced in other Culicidae such as Culex pipiens and Aedes albopictus in response to relatively simple approximations of winter conditions of reduced temperature and photoperiod $[15,16]$. However, multiple studies performed to induce aestivation via oviposition deprivation [17], adult photoperiod and temperature modulation [18], and adult dietary restriction [19], have failed to produce the dramatic lifespan extension typical of aestivation with only a modest increase in median lifespan from 20 to 30 days and maximum life spans of up to 64 days. This study aims to build upon past cues tested for adult aestivation induction. This includes more consideration of temperature and photoperiod changes that may induce or prime mosquito larvae and early adults. As An. coluzzii mosquito numbers decrease prior to the end of the rains and before the numbers of An. gambiae (s.s.) and An. arabiensis decrease [11], there is potential that they are using environmental cues during this time to generate an anticipatory response for aestivation prior to onset of unfavorable dry season conditions. We use temperature, light, and photoperiod conditions from the end of the wet season to prime mosquitoes for aestivation before moving them to temperature and photoperiod conditions consistent with what may be experienced in a refugia during the early dry season. This early dry season period is the coldest of the year for our region, and these cues may potentially be important for the maintenance of aestivation. We evaluate longevity as a primary outcome and describe some morphological and developmental characteristics produced by these conditions.

\section{Methods \\ Mosquito rearing}

Two strains of An. gambiae (s.l.) complex mosquitoes were utilized in this experiment. The first was the Thierola strain of An. coluzzii that were founded as a colony from six wild-caught females from Thierola, Mali (13.6586, - 7.21471) in November 2012 [18]. The second was the N'dokayo strain of An. gambiae (s.s.) (MRA-1278) provided through the Malaria Research and Reference Reagent Resource Center (MR4), originally colonized in 2008 from Cameroon $\left(5^{\circ} 30.723^{\prime} \mathrm{N}, 14^{\circ}\right.$ $\left.07.497^{\prime} \mathrm{E}\right)$ [20]. All mosquito larvae were reared in plastic trays $(30 \times 25 \times 7 \mathrm{~cm})$ with $1.5 \mathrm{l}$ of dechlorinated water. In the first $24 \mathrm{~h}$ after emergence, trays were provided with $5 \mathrm{ml}$ of a $4 \% \mathrm{w} / \mathrm{v}$ baker's yeast slurry [21], and subsequently provided with finely-ground TetraMin fish food ( $\sim .1$ g daily, Tetra Inc., Melle, Germany) [19]. Pupae were picked daily and kept in separate adult cages with sugar provided ad libitum as 10\% karo dark syrup on cotton balls refreshed daily. Normal insectary conditions were $27^{\circ} \mathrm{C}, 85 \%$ humidity, and 12:12 h of light:dark with $30 \mathrm{~min}$ of sunrise/sunset period. All blood feeds were performed using glass, water-jacketed blood feeders, 
with $1 \mathrm{ml}$ of human blood (Interstate Blood Bank, Inc.) hooked to a recirculating water bath kept at $37^{\circ} \mathrm{C}$.

\section{Experimental groups}

To evaluate possible conditions relevant for aestivation induction, we utilized "priming" conditions for mosquitoes based on the downturn in numbers of $A n$. coluzzii mosquitoes at the end of September/October [12]. Using data from a weather monitoring station in Thierola, Mali, we calculated mean daily temperature and humidity profiles for each month and used a climate controlled incubator (I-36VL, Percival Scientific, Perry, IA, USA) to approximate conditions during this time. This temperature and humidity profile alternates between night conditions of $20{ }^{\circ} \mathrm{C}$ and $85 \% \mathrm{RH}$ and day conditions of $32{ }^{\circ} \mathrm{C}$ with $40 \% \mathrm{RH}$ and a 11:13 light: dark cycle (Additional file 1: Figure S1).

To determine initial conditions relevant for aestivation maintenance, a range of refugia-like conditions were chosen based on values to the extreme end of what is likely to be experienced during the Sahelian dry season. In the first experiment, mosquitoes were kept in a climate controlled incubators with initial refugia conditions set to either $18{ }^{\circ} \mathrm{C}$ or $22^{\circ} \mathrm{C}, 8: 16$ light: dark hours of broad spectrum led light (Transcend T8 13.5 and 22W bulbs, Hort Americas, Bedford, TX), and $85 \%$ humidity, with a group left under the priming conditions and a group under standard insectary conditions. During the second experimental trial, the refugia conditions were $20{ }^{\circ} \mathrm{C}, 8: 16 \mathrm{~h}$ of broad spectrum led light, and $85 \%$ humidity. Subsequent experiments were limited to either 20 or $27^{\circ} \mathrm{C}$, with 8 or $12 \mathrm{~h}$ of light and consistent $85 \%$ relative humidity.

\section{Survival analysis and statistics}

To determine the effects from differing environmental conditions, priming, and mosquito species, non-parametric and parametric survival analyses were performed using the survminer and flexsurv packages in $\mathrm{R}$ using R-Studio ( $\mathrm{R}$ version 3.6.0, [22-25]). Not all variables passed the proportional hazards test, so we used accelerated failure time models to determine the effect size of each variable on survival time. We selected the best-fitting model distribution by comparing Akaike's Information Criterion (AIC) values of each survival fit including variables.

\section{Morphological characteristics}

Upon death, individual mosquitoes were placed into a $1.7 \mathrm{ml}$ tube half-filled with desiccant (Silica-gel orange, Cat. No. 10087. Sigma-Aldrich, St. Louis, MO) topped with a small ball of cotton. Mosquitoes were kept at $-20{ }^{\circ} \mathrm{C}$ until dissection. Wing lengths were taken as previously described [18], and wing areas were calculated by determining the convex hull of the fourteen wing landmarks in R, discarding any samples that were missing landmarks. Differences in lengths and areas were compared via Kruskal-Wallis test with Dunn's correction for multiple testing with the dunn.test package in $\mathrm{R}$ [26].

\section{Results \\ Effects of refugia and priming conditions on longevity}

In the first trial simulating a mosquito's move to potential refugia conditions, we compared longevity of An. coluzzii mosquitoes kept at normal insectary conditions $\left(27^{\circ} \mathrm{C}\right.$, $85 \% \mathrm{RH}, 12: 12 \mathrm{~L}: \mathrm{D})$ post-blood meal or moved to $18{ }^{\circ} \mathrm{C}$ / 85\% RH, 8:16 h L:D. Those kept under normal insectary conditions had a median lifespan of 21 days, with a maximum of 34 days, and those moved to $18{ }^{\circ} \mathrm{C}$ had significantly longer median lifespans of 41 days, with a maximum of 80 days ( $n=59 /$ group, $P<0.001$, Fig. 1a). Next, we investigated the larval/pre-blood feed temperature conditions and whether mosquitoes reared under end of wet season "priming" conditions $\left(20-32{ }^{\circ} \mathrm{C}\right.$ daily), then transferred to potential refugia conditions of $18{ }^{\circ} \mathrm{C}, 22^{\circ} \mathrm{C}$, $27{ }^{\circ} \mathrm{C}$, or kept under end of wet season priming conditions would have increased longevity. For mosquitoes primed with end of wet season conditions then moved to $18{ }^{\circ} \mathrm{C}, 22^{\circ} \mathrm{C}, 27^{\circ} \mathrm{C}$, or kept under priming conditions had median lifespans of 50, 46, 26 and 27 days and maximum lifespans of 102, 89, 44 and 52 days, respectively. Median lifespans were significantly different between normal insectary conditions and $18{ }^{\circ} \mathrm{C}, 22{ }^{\circ} \mathrm{C}$ (adjusted $P$-values $<0.001$, Fig. 1b).

\section{Effect of simulated induction and maintenance of aestivation on longevity}

Once the positive longevity effects of both priming and the tested refugia conditions had been established, we performed three additional survival experiments to determine interactions of photoperiod, priming, species, and temperature on the longevity phenotype (Fig. 2). Overall, as in the first experiments, we found significant extension of lifespan with both $\mathrm{M}$ and $\mathrm{S}$ form mosquitoes when maintained in cooler, darker environments than general insectary conditions with median survival ranging from 18 days $(95 \% \mathrm{CI} 18-21)$ in $27{ }^{\circ} \mathrm{C} / 12: 12 \mathrm{~h} \mathrm{~L}: \mathrm{D}$ / unprimed / S-form mosquitoes to a maximum median survival of 63 days (95\% CI 55-69 days) in $20^{\circ} \mathrm{C} / 8: 16 \mathrm{~h}$ L:D / primed / S-form mosquitoes (Table 1). Priming had variable results depending on condition and species, i.e. at $20{ }^{\circ} \mathrm{C}$ with $12: 12 \mathrm{~h} \mathrm{~L}: \mathrm{D}$ cycle, priming increased longevity for both $\mathrm{M}$ and $\mathrm{S}$ mosquitoes (median survival from 38 to 49 days and from 38 to 50 days, without/with priming respectively), whereas at $20{ }^{\circ} \mathrm{C}$ with $8: 16 \mathrm{~h} \mathrm{~L}: \mathrm{D}$ 
cycle, only S-form mosquitoes increased survival with priming (median survival of 46.5 without priming and 63 days with priming in S-form and 49 without priming and 45 days in $\mathrm{M}$-form with priming).

To better understand the contribution of the treatment variables, we utilized an accelerated failure time model using a Weibull distribution, chosen as the best fit of our data based on AIC (Additional file 3: Table S1). Using this model, we evaluated the specific effects of each component via their event time ratio (time to death). We found that temperature, photoperiod, priming, and species significantly increased survival $(P$-values of $<0.001,<0.001,<0.001$ and 0.009 , event time ratios of $2.02,1.24,1.19,1.12$, respectively, Table 2), indicating that storage at $20^{\circ} \mathrm{C}$ vs $27^{\circ} \mathrm{C}$ doubles survival, $8 \mathrm{~h}$ of light a day vs 12 increased survival by $24 \%$, end of wet season priming conditions over standard insectary increased survival by $19 \%$, and $M$-form overall had slightly higher survival across all conditions by $12 \%$. As we expected the species to differ in their response to these variables, we allowed for an interaction term with species. These were largely insignificant, though there was an unexpected negative relationship with priming and $\mathrm{M}$-form mosquitoes (ETR 0.81, $P<0.001$ ).

\section{Wing morphology under tested conditions}

As priming began in the larval environment, and larval conditions are known to affect adult morphology [27], we investigated the role to which these environmental conditions modified adult size measured via wing length and area. Priming had a strong effect on wing lengths for both $\mathrm{M}$ and $\mathrm{S}$ form mosquitoes $(2.82 \mathrm{~mm}$ mean wing length without priming and $3.13 \mathrm{~mm}$ with priming for M-form, $2.87 \mathrm{~mm}$ without priming and $3.06 \mathrm{~mm}$ with for S-form, Additional file 4: Figure S3). Increase in wing lengths with priming was significantly different between unprimed and primed mosquitoes for both species via Dunn's test with adjustment for multiple comparisons $(P$-adj $<0.001)$. However, correlations of wing areas and age at death were not consistent (Additional file 5: Figure S4), indicating that body size is not a sole indicator of potential longevity.

\section{Proof of viability post climatic modulation}

To evaluate the viability of the longevity-induced state, we moved separate groups of mosquitoes that had lived 66 days in the refugia condition (70 days-old) without males to normal insectary conditions $\left(27{ }^{\circ} \mathrm{C}, 12: 12 \mathrm{~h}\right.$ L:D) and provided an oviposition cup (without blood meal). No eggs were laid in these oviposition cups until the females were allowed to blood feed (day 72 of life) at which point eggs were laid (77 eggs/18 fed females primed S-form, 13 eggs/10 fed females primed M-form). Eggs were hatched and allowed to develop until adulthood. This was successful for primed $\mathrm{M}$ and $\mathrm{S}$ form mosquitoes (20 emerged S-form adults, 1 emerged M-form adult).

\section{Discussion}

Aestivation appears to be essential to the persistence of mosquitoes in arid, Sahelian regions [28-30]; however, we have limited to no understanding of the mechanisms, inductive cues, or prevalence of aestivation in Anopheles species [19]. A primary reason behind this limited knowledge of aestivation is the current inability to replicate this state under modern laboratory conditions $[18$, 31]. This is counter to historic studies which successfully induced high longevity in mosquitoes recently collected from the field (156 and 206 days, respectively) [10, 32], but reported limited details on how this induction was achieved. To the best of our knowledge, this study is the first of the modern era to extend the maximum lifespan of Anopheles mosquitoes over 100 days, with 2.2-3.5-fold increase in maximum longevity over standard insectary conditions depending on species. However, we failed to reach the dramatic extension of these historic studies or the 7-fold extension known to be possible in wild Anopheles [33]. The lifespans present are significantly higher than past studies attempting to induce aestivation states [17-19]; however there are no known markers of aestivation in Anopheles, thus making the declaration of this state unequivocally as aestivation difficult. Furthermore, the demonstration (though on a small scale) that mosquitoes after $2+$ months in refugia, when returned to wet season conditions, will blood feed and lay viable eggs, shows the viability of these potential aestivators to restart a population (even in absence of fresh male mosquitoes).

As we do not know exact refugia conditions in the wild, but know that Anopheles mosquitoes prefer cooler, more humid refugia conditions [34], this study uses realistic, but likely somewhat exaggerated, climate conditions to induce aestivation with a reduced temperature and photoperiod. Temperature was the major climatic variable found to extend lifespan in this study, accounting for roughly a doubling of longevity alone (Table 2 ). The longevity of some dipterans is known to increase below $27{ }^{\circ} \mathrm{C}$ (our normal insectary temperature), i.e. Calliphora stygia blowflies have an average longevity of 27.7 days at $25{ }^{\circ} \mathrm{C}, 45.1$ days at $20{ }^{\circ} \mathrm{C}$, and 90.8 days at $12{ }^{\circ} \mathrm{C}$ [35] and Culex pipiens female mosquitoes can be kept in a non-diapausing cold storage for up to 102 days at $6{ }^{\circ} \mathrm{C}$ [36]. However, An. gambiae (s.s.) lifespan has been reported largely to decrease in longevity below $20^{\circ} \mathrm{C}$ with mean survival of 31.77 days for females at $80 \% \mathrm{RH}$ and 

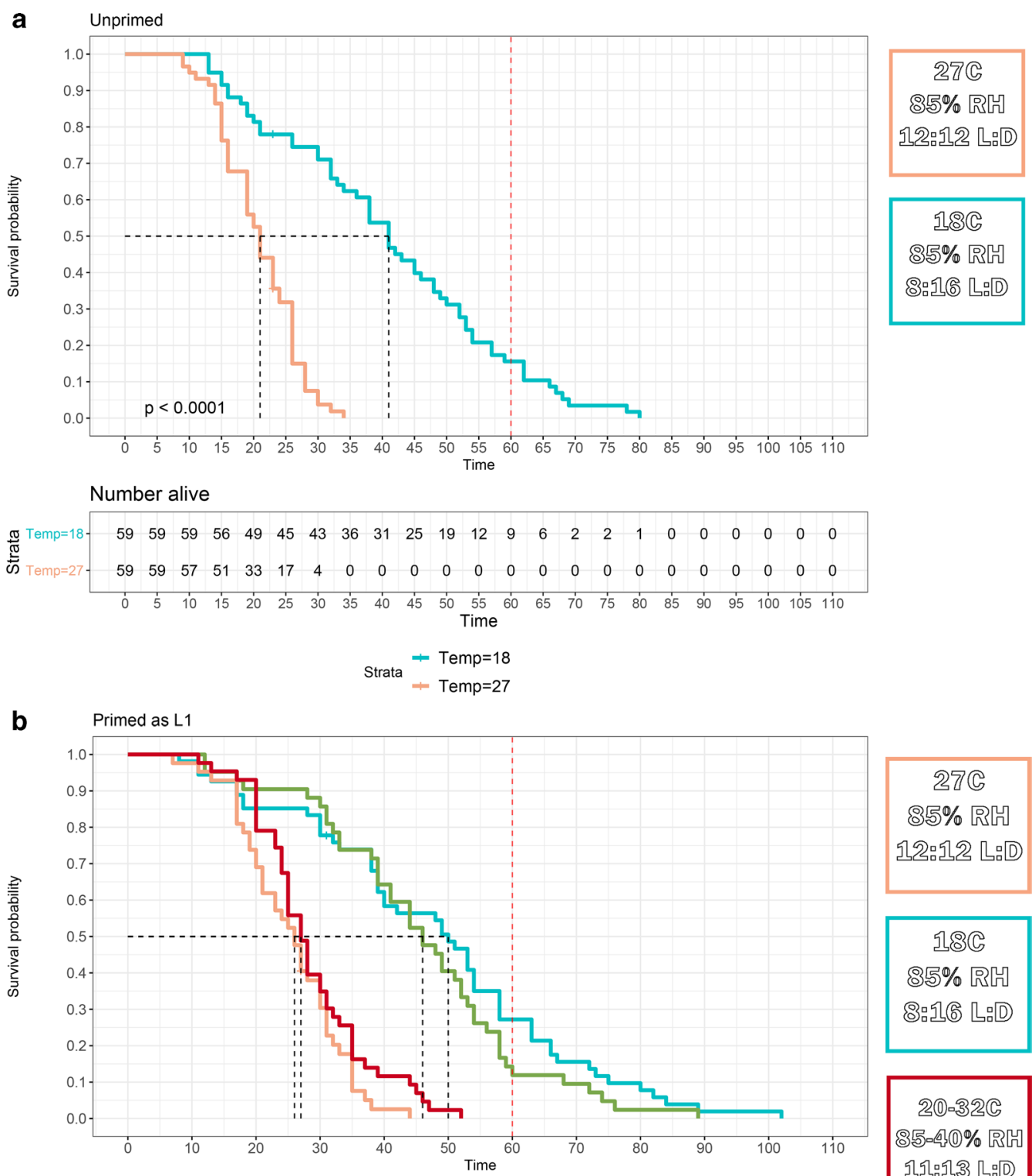

Number alive

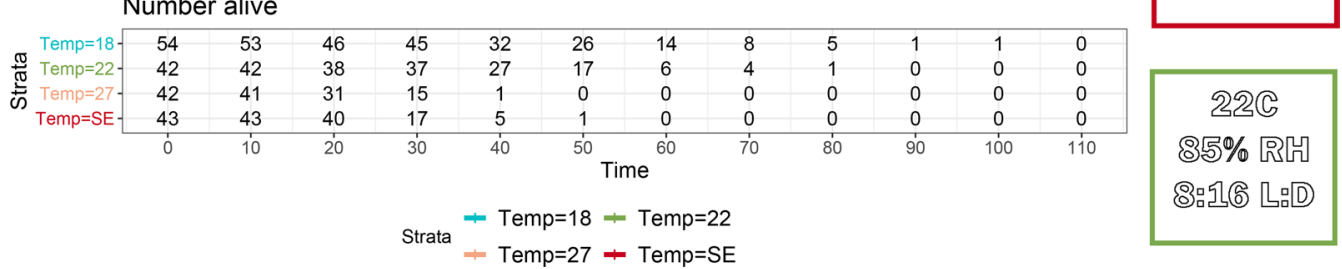

Fig. 1 Kaplan-Meier survival curves to evaluate priming and refugia conditions. a Blood-fed, unprimed An. coluzzii (M-form) mosquitoes reared in the listed conditions $\left(18^{\circ} \mathrm{C}\right.$ significantly higher survival, $\left.P<0.001\right)$. b Blood-fed, primed from $\mathrm{L} 1$ in end of wet-season conditions, An. coluzzii mosquitoes reared in the listed conditions $\left(18^{\circ} \mathrm{C}, 22^{\circ} \mathrm{C}\right.$ significantly higher survival than $27^{\circ} \mathrm{C}$ and $\mathrm{SE}$ conditions $P$-adj $<0.001 .18^{\circ} \mathrm{C}$ vs $22^{\circ} \mathrm{C}$ and $27^{\circ} \mathrm{C}$ vs SE not significantly different, $P$-adj $>0.11$ )

maximum overall survival at $15^{\circ} \mathrm{C} / 100 \% \mathrm{RH}$ of less than 70 days [37]. Additionally, this relationship with temperature appears to be variable, with another study reporting median survival at a similar temperature $\left(21^{\circ} \mathrm{C}\right)$ of $23.2-$ 24.9 days [38]. The closest reference to the over 100-day survival seen in this study was with recently colonized 
Effects of Photoperiod with Priming - All merge

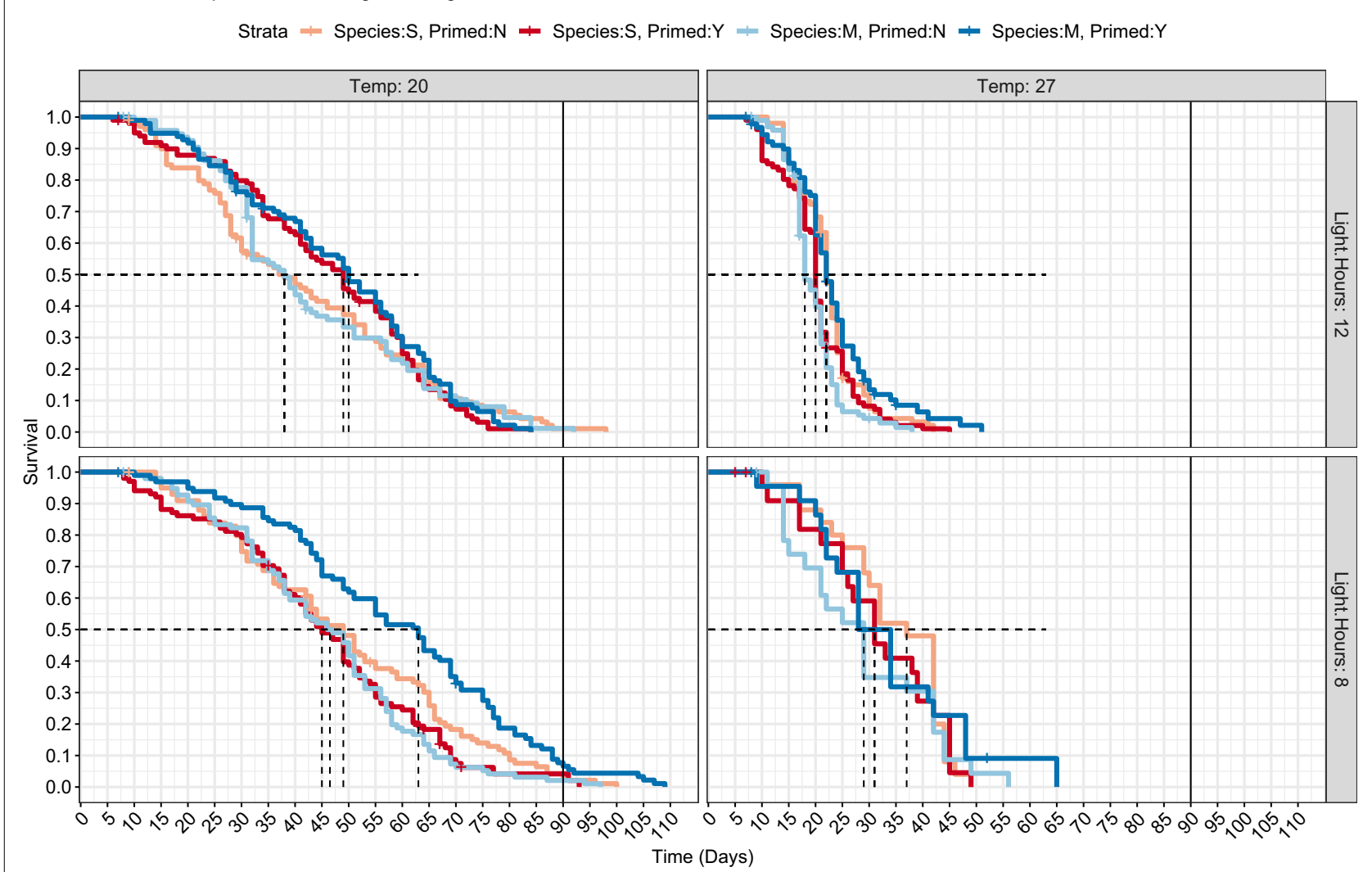

Fig. 2 Kaplan-Meier survival curves for each experimental group tested. The data from three independent trials are combined ( $n=100 \mathrm{mosquitoes/}$ group) and presented for all groups except for $27^{\circ} \mathrm{C} / 8: 16 \mathrm{~h} \mathrm{L:D}$ cycle which was added during the last replicate $(n=25 \mathrm{mosquitoes} / \mathrm{group})$. All $20^{\circ} \mathrm{C}$ significantly different from $27^{\circ} \mathrm{C}(P$-adj $<0.01)$. Priming significant for $\mathrm{S}$-form mosquitoes at $20^{\circ} \mathrm{C} / 8: 16 \mathrm{~h}$ photoperiod $(P$-adj $<0.001)$

mosquitoes held in dry season semi-field environments (mean temperatures of $\sim 22{ }^{\circ} \mathrm{C}$ ) in Kenya, with maximum lifespans reaching 92 days [39]. This may indicate the importance of using recently collected laboratory colonies for future lifespan studies and may also indicate that temperature alone is not the sole driver of long-lived states.

The second most significant variable found in this study was photoperiod. While this variable had previously been explored in the context of Anopheles aestivation [18], the light duration was $11 \mathrm{~h}$ /day, rather than $8 \mathrm{~h} /$ day used in this study. In New World An. quadrimaculatus and An. crucians, a 8:16 h L:D cycle induced greater longevity, though this effect was modest (mean life span 25.64 vs 19.33 days in female An. quadrimaculatus, 20.43 vs 17.24 in female An. crucians) [40, 41]. The Senegalese grasshopper (Oedaleus senegalensis) collected in Mourdiah, Mali $(14.472,-7.473)$ have shown a strong interaction between photoperiod and temperature in diapause induction in eggs [42], with maximum induction at $25^{\circ} \mathrm{C}$ (the lowest temperature tested) and less than $12 \mathrm{~h}$ of light. However, this location has a slightly higher latitude, and thus a greater seasonal shift in day length, than the original collection location of our M-form strain. Recent work has shown that conditions that induce winter diapause in European Drosophila spp. can also induce the state in some African/tropical fly strains [43, 44]. This suggests that diapause may be a generalized survival mechanism that is often preserved in tropical taxa and can be utilized to bridge the gap between seasonally favorable climatic conditions. This may indicate that by pushing our mosquitoes into exaggerated, but not necessarily impossible, temperature/light refugia conditions we increased our chances of entering a long-lived state. This exaggeration may be necessary as laboratory conditions do not recapitulate all of the possible cues present in the field. The exaggeration of photoperiod beyond what is expected in Mali may also have pushed the S-form, An. gambiae (s.s.), mosquitoes colonized from Cameroon to also have similar longevity in response to these cues as An. coluzzii, 
Table 1 Conditions and survival characteristics for priming and adult rearing temperature conditions

\begin{tabular}{|c|c|c|c|c|c|c|c|c|c|}
\hline Temp & Species & Light. hours & Primed $^{a}$ & $n$ & Mean & SE & Median & $95 \% \mathrm{Cl}$ & Max \\
\hline 27 & M & 12 & $\mathrm{~N}$ & 101 & 21.34 & 0.62 & 21 & $21-22$ & 42 \\
\hline 27 & M & 12 & Y & 101 & 19.28 & 0.69 & 19 & $19-20$ & 45 \\
\hline 27 & M & 8 & N & 25 & 33.20 & 2.09 & 36 & $29-41$ & 49 \\
\hline 27 & M & 8 & Y & 25 & 30.45 & 2.43 & 30 & $25-41$ & 49 \\
\hline 27 & S & 12 & N & 100 & 18.55 & 0.51 & 17 & $17-20$ & 38 \\
\hline 27 & S & 12 & Y & 100 & 22.50 & 0.97 & 21 & $20-23$ & 51 \\
\hline 27 & S & 8 & N & 25 & 27.74 & 2.71 & 28 & $20-41$ & 56 \\
\hline 27 & $S$ & 8 & Y & 25 & 32.64 & 3.03 & 30 & $27-41$ & 65 \\
\hline 20 & M & 12 & N & 100 & 40.03 & 2.02 & 37 & $29-48$ & 98 \\
\hline 20 & M & 12 & Y & 100 & 44.80 & 1.85 & 48 & $41-54$ & 84 \\
\hline 20 & M & 8 & N & 101 & 46.84 & 1.95 & 48 & $42-54$ & 100 \\
\hline 20 & M & 8 & Y & 101 & 43.67 & 1.86 & 44 & $40-49$ & 93 \\
\hline 20 & S & 12 & N & 100 & 41.34 & 1.86 & 37 & $31-42$ & 92 \\
\hline 20 & S & 12 & Y & 100 & 46.48 & 1.86 & 49 & $42-55$ & 84 \\
\hline 20 & S & 8 & N & 100 & 44.02 & 1.69 & 45.5 & $41-50$ & 97 \\
\hline 20 & S & 8 & Y & 100 & 55.20 & 1.84 & 62 & $54-68$ & 109 \\
\hline
\end{tabular}

Notes: See also Additional file 2: Figure S2. Three replicates were performed for all groups (group size $\sim 25, \sim 50$, and 25 per replicate) except for $27^{\circ} \mathrm{C}$ and $8: 16 \mathrm{~L}: \mathrm{D}$ which was added during the final replicate (group size 25)

$\mathrm{Cl}$, confidence interval; Max, maximum; SE, standard error

a Primed mosquitoes kept in a 11:13 Light:Dark (L:D), 40-85\% relative humidity (RH), $20-32^{\circ} \mathrm{C}$ daily cycle (see Additional file $1:$ Figure S1) until their first blood meal at which they were moved into the listed temperature and light hour conditions. Non-priming conditions are standard $12: 12 \mathrm{~L}: \mathrm{D}, 85 \% \mathrm{RH}, 27^{\circ} \mathrm{C}$

Table 2 Significance of individual variables towards survival as estimated using an Accelerated Failure Time model with a Weibull distribution

\begin{tabular}{|c|c|c|c|c|c|}
\hline Variable & Value & SE & $z$ & $P$ & ETR \\
\hline (Intercept) & 3.107895 & 0.030706 & 101.2135 & 0 & 22.37 \\
\hline Temp $\left(20^{\circ} \mathrm{C}\right)$ & 0.704108 & 0.031994 & 22.00753 & $2.4 \mathrm{E}-107$ & 2.02 \\
\hline Light. Hours (8:16) & 0.218615 & 0.0315 & 6.940067 & $3.92 \mathrm{E}-12$ & 1.24 \\
\hline Primed (Yes) & 0.1703 & 0.030607 & 5.564113 & $2.63 E-08$ & 1.19 \\
\hline Species (M) & 0.109571 & 0.042466 & 2.580224 & 0.009874 & 1.12 \\
\hline Temp20: SpeciesM & -0.02792 & 0.044161 & -0.63232 & 0.527178 & 0.97 \\
\hline Light. Hours8:SpeciesM & -0.03256 & 0.043985 & -0.74027 & 0.459134 & 0.97 \\
\hline PrimedY:SpeciesM & -0.20976 & 0.042588 & -4.92548 & $8.42 \mathrm{E}-07$ & 0.81 \\
\hline Log(scale) & -0.99224 & 0.022042 & -45.015 & 0 & 0.37 \\
\hline
\end{tabular}

Notes: Significant variables are bolded, and event time ratios (ETR) are presented. These can be interpreted as the time to death of the listed condition for that variable (i.e. a mosquito at Temp $20^{\circ} \mathrm{C}$ has double the time to death of a mosquito at $27^{\circ} \mathrm{C}$ ). Interaction terms are designated with a colon between variables

even though the $\mathrm{S}$-form mosquitoes are not believed to be aestivating in Mali [12]. Additionally, by pushing the $\mathrm{S}$-form mosquitoes into a potential diapause by extended photoperiod may point to why the interaction term in our model failed to show an effect with temperature or light with species (Table 2).

Consistent with previous studies investigating possible dry-season/aestivation-induction conditions [17, 18 ], wing sizes were significantly increased in our dryseason priming conditions (Additional file 4: Figure S3).
However, there was not a consistent correlation between the wing size and length of life (Additional file 5: Figure S4). As wing size (a good proxy for overall body size) of mosquitoes is primarily driven by larval environments [45], and aestivating mosquitoes are thought to be surviving as adults $[12,31,33,46]$, the exact role of body size in aestivation is unknown, though seasonal differences have been reported in the field [47]. We note that these mosquitoes were blood-fed, which does increase longevity over non-blood-fed mosquitoes in the laboratory 
[48], but can potentially increase mortality in real world conditions due to risk while blood-feeding and predation post-feeding $[49,50]$. The role of oviposition deprivation in these conditions is also currently unknown, though has been investigated under standard laboratory conditions [17]. The role of nutrition, long known to play a role in longevity $[19,51-54]$, may also be driving some of the morphological associations seen in this state. Additionally, nutrition may be modulated by how temperature is affecting the overall activity of the mosquitoes. A reduction in activity could also have a reduction in sugar-feeding, which may contribute to the increase in longevity seen.

\section{Conclusions}

This work represents a significant increase over past attempts to induce aestivation in laboratory Anopheles gambiae (s.l.) mosquitoes, possibly representing the first modern recapitulation of the state in the laboratory. Additional fine tuning of priming and maintenance conditions may further push longevity. Future work based on the treatments described here is necessary to validate the state induced in mosquitoes in these conditions through analysis of transcriptional changes [15, 55, 56], ovary follicle length [57-59], lipid content [57], and sugar utilization [60]. These should be contrasted with field-collected samples which may better represent the full expression of the aestivation phenotype. Finally, this work may provide a platform to assess how longevity and aestivation affects Plasmodium competence and the possibility of a parasite reservoir in aestivating mosquitoes which may impact future elimination campaigns.

\section{Supplementary information}

Supplementary information accompanies this paper at https://doi. org/10.1186/s13071-020-04276-y.

Additional file 1: Figure S1. Temperature and Humidity profiles for
Thierola, Mali (red, orange) and the priming incubator (green, blue) as
recorded by a HOBO temperature and humidity logger.

Additional file 2: Figure S2. Boxplot and raincloud [61] plots showing the date of death ranges and distributions for each of the experimental groups.

Additional file 3: Table S1. Akaike's information criterion values for distributions tested using accelerated failure time models.

Additional file 4: Figure S3. Raincloud plot indicating measured wing lengths as a proxy for body size for primed and unprimed mosquitoes. Boxplot, individual points, and density distribution are shown. Point shapes indicate which replicate the lengths are from.

Additional file 5: Figure S4. Correlations of wing areas and survival for replicates 2 and 3 of the experiment. No consistent correlations between wing area and lifespan were found between the two experiments.

\section{Abbreviations}

$\mathrm{RH}$ : Relative humidity; L:D: Daily light to dark hours; M-form: Anopheles coluzzii; S-form: Anopheles gambiae (s.s.); AIC: Akaike information criterion.

\section{Acknowledgements}

We thank BEl resources and the original depositor for the N'dokayo strain of An. gambiae (s.s.) mosquitoes used in this study. We thank Andre Laughinghouse, Kevin Lee, and Afsana Hossain for assistance in mosquito rearing. We thank Sam Moretz and Tom Wellems for their support of the project.

\section{Authors' contributions}

BK RF TL designed the study. MS dissected and digitized wings. BK LV LG took daily survival data. BKTL analyzed the data. BKTL wrote the manuscript. All authors edited the manuscript. All authors read and approved the final manuscript.

\section{Funding}

This study was supported by the Division of Intramural Research, National Institute of Allergy and Infectious Diseases, National Institutes of Health, Bethesda MD.

\section{Availability of data and materials}

The datasets supporting the conclusions of this article are available in the zenodo and github repositories, at: zenodo: https://doi.org/10.5281/zenod 0.3735020 and https://github.com/benkraj/aestivation.manu.files.scripts.

\section{Ethics approval and consent to participate}

Not applicable.

\section{Consent for publication}

Not applicable.

\section{Competing interests}

The authors declare that they have no competing interests.

Received: 8 April 2020 Accepted: 3 August 2020

Published online: 12 August 2020

References

1. WHO. World Malaria Report 2018. Geneva: World Health Organization; 2019. https://www.who.int/malaria/publications/world-malaria-repor t-2018/report/en/.

2. Bhatt S, Weiss DJ, Cameron E, Bisanzio D, Mappin B, Dalrymple U, et al. The effect of malaria control on Plasmodium falciparum in Africa between 2000 and 2015. Nature. 2015;526:207-11.

3. Weiss DJ, Lucas TCD, Nguyen M, Nandi AK, Bisanzio D, Battle KE, et al. Mapping the global prevalence, incidence, and mortality of Plasmodium falciparum, 2000-17: a spatial and temporal modelling study. Lancet. 2019;394:322-31.

4. Flaxman AD, Fullman N, Otten MW, Menon M, Cibulskis RE, Ng M, et al. Rapid scaling up of insecticide-treated bed net coverage in Africa and its relationship with development assistance for health: a systematic synthesis of supply, distribution, and household survey data. PLoS Med. 2010;7:e1000328.

5. PMI | Africa IRS (AIRS) Project Indoor Residual Spraying (IRS 2) Task Order Six. 2017. Mali End of Spray Report. Bethesda, MD: Abt Associates. 2017.

6. Ranson H, Lissenden N. Insecticide resistance in African Anopheles mosquitoes: a worsening situation that needs urgent action to maintain malaria control. Trends Parasitol. 2016;32:187-96.

7. Killeen GF, Fillinger U, Kiche I, Gouagna LC, Knols BGJ. Eradication of Anopheles gambiae from Brazil: lessons for malaria control in Africa? Lancet Infect Dis. 2002;2:618-27.

8. Shousha AT. Species-eradication: the eradication of Anopheles gambiae from Upper Egypt, 1942-1945. Bull World Health Organ. 1948;1:309-52. 
9. Stephens JWW, Christophers SR. The practical study of malaria and other blood parasites. 3rd edn. Liverpool: The University Press; London: Williams and Norgate; 1908.

10. Holstein MH. Biology of Anopheles gambiae: research in French West Africa. Geneva: World Health Organization; 1954. https://apps.who. int/iris/bitstream/handle/10665/40727/WHO_MONO_9.pdf?seque nce $=1$ \&isAllowed $=y$.

11. Omer SM, Cloudsley-Thompson JL. Survival of female Anopheles gambiae Giles through a 9-month dry season in Sudan. Bull World Health Organ. 1970;42:319-30

12. Dao A, Yaro AS, Diallo M, Timbiné $S$, Huestis DL, Kassogué $Y$, et al. Signatures of aestivation and migration in Sahelian malaria mosquito populations. Nature. 2014;516:387-90.

13. Huestis DL, Dao A, Diallo M, Sanogo ZL, Samake D, Yaro AS, et al. Windborne long-distance migration of malaria mosquitoes in the Sahel. Nature. 2019:574:404-8.

14. Yaro AS, Traoré Al, Huestis DL, Adamou A, Timbiné S, Kassogué Y, et al. Dry season reproductive depression of Anopheles gambiae in the Sahel. J Insect Physiol. 2012;58:1050-9.

15. Kang DS, Cotten MA, Denlinger DL, Sim C. Comparative transcriptomics reveals key gene expression differences between diapausing and nondiapausing adults of Culex pipiens. PLoS ONE. 2016;11:e0154892.

16. Poelchau MF, Reynolds JA, Elsik CG, Denlinger DL, Armbruster PA. RNASeq reveals early distinctions and late convergence of gene expression between diapause and quiescence in the Asian tiger mosquito, Aedes albopictus. J Exp Biol. 2013;216:4082-90.

17. Artis ML, Huestis DL, Lehmann T. The effects of oviposition-site deprivation on longevity and bloodfeeding rate in Anopheles gambiae. Parasit Vectors. 2014;7:163.

18. Huestis DL, Artis ML, Armbruster PA, Lehmann T. Photoperiodic responses of Sahelian malaria mosquitoes Anopheles coluzzii and An. arabiensis. Parasit Vectors. 2017;10:621.

19. Faiman R, Solon-Biet S, Sullivan M, Huestis DL, Lehmann T. The contribution of dietary restriction to extended longevity in the malaria vector Anopheles coluzzii. Parasit Vectors. 2017;10:156.

20. Gimonneau G, Bayibeki AN, Baldet T, Awono-Ambene PH, Simard F. Life history consequences of larval foraging depth differ between two competing Anopheles mosquitoes. Ecol Entomol. 2015;40:143-9.

21. Benedict MQ. Methods in Anopheles research. MR4 2007. https://www. beiresources.org/portals/2/MR4/MR4_Publications/Methods\%20in\%20 Anopheles\%20Research\%202014/2014MethodsinAnophelesResearch ManualFullVersionv2tso.pdf.

22. RStudio Team. RStudio: Integrated Development Environment for R. 2015

23. R Development Core Team. R: A language and environment for statistical computing. Vienna: R Foundation for Statistical Computing; 2019. https:// www.R-project.org/.

24. Jackson CH. Flexsurv: a platform for parametric survival modeling in R. J Stat Softw. 2016;70:1-33.

25. Kassambara A, Kosinski M, Biecek P. survminer: Drawing Survival Curves using ggplot2. 2019. http://www.sthda.com/english/rpkgs/survminer/

26. Dinno A. dunn.test: Dunn's Test of Multiple Comparisons Using Rank Sums. 2017. http://cran.r-project.org/package=dunn.test.

27. Lyimo EO, Takken W, Koella JC. Effect of rearing temperature and larval density on larval survival, age at pupation and adult size of Anopheles gambiae. Entomol Exp Appl. 1992;63:265-71.

28. North AR, Godfray HCJ. Modelling the persistence of mosquito vectors of malaria in Burkina Faso. Malar J. 2018;17:140.

29. Adamou A, Dao A, Timbine S, Kassogué Y, Yaro AS, Diallo M, et al. The contribution of aestivating mosquitoes to the persistence of Anopheles gambiae in the Sahel. Malar J. 2011;10:151.

30. Magombedze G, Ferguson NM, Ghani AC. A trade-off between dry season survival longevity and wet season high net reproduction can explain the persistence of Anopheles mosquitoes. Parasit Vectors. 2018;11:576.

31. Huestis DL, Lehmann T. Ecophysiology of Anopheles gambiae s.l.: persistence in the Sahel. Infect Genet Evol. 2014;28:648-61.

32. Omer SM, Cloudsley-Thompson JL. Dry season biology of Anopheles gambiae Giles in the Sudan. Nature. 1968;217:879-80.
33. Lehmann T, Dao A, Yaro AS, Adamou A, Kassogue Y, Diallo M, et al. Aestivation of the African malaria mosquito, Anopheles gambiae in the Sahel. Am J Trop Med Hyg. 2010;83:601-6.

34. Kessler S, Guerin PM. Responses of Anopheles gambiae, Anopheles stephensi, Aedes aegypti, and Culex pipiens mosquitoes (Diptera: Culicidae) to cool and humid refugium conditions. J Vector Ecol. 2008;33:145-9.

35. Kelly MA, Zieba AP, Buttemer WA, Hulbert AJ. Effect of temperature on the rate of ageing: an experimental study of the blowfly Calliphora stygia. PLOS ONE. 2013:8:e73781.

36. Rinehart JP, Yocum GD, Leopold RA, Robich RM. Cold storage of Culex pipiens in the absence of diapause. J Med Entomol. 2010;47:1071-6.

37. Bayoh MN. Studies on the development and survival of Anopheles gambiae sensu stricto at various temperatures and relative humidities. PhD Thesis, Durham University, Durham, United Kingdom; 2001.

38. Shapiro LLM, Whitehead SA, Thomas MB. Quantifying the effects of temperature on mosquito and parasite traits that determine the transmission potential of human malaria. PLoS Biol. 2017;15:e2003489.

39. Afrane YA, Zhou G, Lawson BW, Githeko AK, Yan G. Effects of microclimatic changes caused by deforestation on the survivorship and reproductive fitness of Anopheles gambiae in western Kenya highlands. Am J Trop Med Hyg. 2006;74:772-8.

40. Lanciani CA, Anderson JF. Effect of photoperiod on longevity and metabolic rate in Anopheles quadrimaculatus. J Am Mosq Control Assoc. 1993;9:158-63.

41. Lanciani CA. Photoperiod and longevity in Anopheles crucians. J Am Mosq Control Assoc. 1993;9:308-12.

42. Colvin J, Cooter RJ. Diapause induction and coloration in the Senegalese grasshopper, Oedaleus senegalensis. Physiol Entomol. 1995;20:13-7.

43. Zonato V, Collins L, Pegoraro M, Tauber E, Kyriacou CP. Is diapause an ancient adaptation in Drosophila? J Insect Physiol. 2017;98:267-74.

44. Pegoraro M, Zonato V, Tyler ER, Fedele G, Kyriacou CP, Tauber E. Geographical analysis of diapause inducibility in European Drosophila melanogaster populations. J Insect Physiol. 2017;98:238-44.

45. Barreaux AMG, Stone CM, Barreaux P, Koella JC. The relationship between size and longevity of the malaria vector Anopheles gambiae (s.s.) depends on the larval environment. Parasit Vectors. 2018:11:485.

46. Lehmann T, Dao A, Yaro AS, Huestis DL, Diallo M, Timbiné S, et al. Phenotypic divergence among the members of the African malaria mosquitoes and strategies of persistence throughout the dry season. Malar J. 2014;13(Suppl. 1):O2.

47. Huestis DL, Yaro AS, Traoré Al, Dieter KL, Nwagbara Jl, Bowie AC, et al. Seasonal variation in metabolic rate, flight activity and body size of Anopheles gambiae in the Sahel. J Exp Biol. 2012;215:2013-21.

48. Gary RE, Foster WA. Effects of available sugar on the reproductive fitness and vectorial capacity of the malaria vector Anopheles gambiae (Diptera: Culicidae). J Med Entomol. 2001;38:22-8.

49. Day JF, Edman JD. Mosquito engorgement on normally defensive hosts depends on host activity patterns. J Med Entomol. 1984;21:732-40.

50. Schwartz A, Koella JC. Trade-offs, conflicts of interest and manipulation in Plasmodium-mosquito interactions. Trends Parasitol. 2001;17:189-94.

51. Clifton ME, Noriega FG. The fate of follicles after a blood meal is dependent on previtellogenic nutrition and juvenile hormone in Aedes aegypti. J Insect Physiol. 2012:58:1007-19.

52. Simpson SJ, Clissold FJ, Lihoreau M, Ponton F, Wilder SM, Raubenheimer D. Recent advances in the integrative nutrition of arthropods. Annu Rev Entomol. 2015;60:293-311.

53. Simpson SJ, Raubenheimer D. Caloric restriction and aging revisited: the need for a geometric analysis of the nutritional bases of aging. J Gerontol A, Biol Sci Med Sci. 2007;62:707-13.

54. Simpson SJ, Raubenheimer D. Assuaging nutritional complexity: a geometrical approach. Proc Nutr Soc. 1999;58:779-89.

55. Ragland GJ, Keep E. Comparative transcriptomics support evolutionary convergence of diapause responses across Insecta. Physiol Entomol. 2017:42:246-56.

56. Poelchau MF, Reynolds JA, Denlinger DL, Elsik CG, Armbruster PA. A de novo transcriptome of the Asian tiger mosquito, Aedes albopictus, to identify candidate transcripts for diapause preparation. BMC Genomics. 2011;12:619. 
57. Sim C, Denlinger DL. Insulin signaling and FOXO regulate the overwintering diapause of the mosquito Culex pipiens. Proc Natl Acad Sci USA. 2008;105:6777-81.

58. Meuti ME, Short CA, Denlinger DL. Mom matters: diapause characteristics of Culex pipiens-Culex quinquefasciatus (Diptera: Culicidae) hybrid mosquitoes. J Med Entomol. 2015;52:131-7.

59. Nelms BM, Macedo PA, Kothera L, Savage HM, Reisen WK. Overwintering biology of Culex (Diptera: Culicidae) mosquitoes in the Sacramento Valley of California. J Med Entomol. 2013:50:773-90.

60. Robich RM, Denlinger DL. Diapause in the mosquito Culex pipiens evokes a metabolic switch from blood feeding to sugar gluttony. Proc Natl Acad Sci USA. 2005;102:15912-7.
61. Allen M, Poggiali D, Whitaker K, Marshall TR, Kievit RA. Raincloud plots: a multi-platform tool for robust data visualization. [version 1; peer review: 2 approved]. Wellcome Open Res. 2019;4:63.

\section{Publisher's Note}

Springer Nature remains neutral with regard to jurisdictional claims in published maps and institutional affiliations.
Ready to submit your research? Choose BMC and benefit from:

- fast, convenient online submission

- thorough peer review by experienced researchers in your field

- rapid publication on acceptance

- support for research data, including large and complex data types

- gold Open Access which fosters wider collaboration and increased citations

- maximum visibility for your research: over $100 \mathrm{M}$ website views per year

At BMC, research is always in progress.

Learn more biomedcentral.com/submissions 